\title{
A CONTRIBUTION TO THE GENETICS OF GARGOYLISM
}

\author{
BY
}

\section{ROBERT C. CUNNINGHAM}

From the Royal Albert Hospital, Lancaster, and the Department of Fublic Health, Essex County Council

The first clinical description of this syndrome by Hunter (1917) was quickly followed by that of Hurler (1919). Later, Ellis, Sheldon, and Capon (1936) coined the name "gargoylism" because of the cephalic, facial, and thoracic grotesqueness reminiscent of the figures on the Cathedral of Notre Dame in Paris.

The fundamental defect, as stated by Jackson (1951), is twofold, namely, a chondro-osseous dystrophy together with the storage of an abnormal macro-molecular substance. Involvement of the skull, spine, ribs, and long bones, storage deposition in the reticulo-endothelial system and in widespread parenchymatous and connective tissue, lead to the clinical picture most characteristic of gargoylism. Since this picture is important in the diagnosis of cases by inference, it will be briefly described here.

Most authors agree that the head is enlarged with well marked supra-orbital ridges, a squat nose with depressed bridge, thick lips, strong teeth, a large tongue, apparently low-set ears, and a short neck. The eyes may or may not have corneal opacities. The hair is thick, especially on the scalp and eyebrows. The lower part of the thorax tends to flare and the spine is kyphotic. The abdomen appears large and is often herniated. There is hepatosplenomegaly but sometimes the liver, alone, is palpable. The genitalia are infantile in type. The long bones are stunted, with a variety of orthopaedic defects, the most noticeable of which is restriction of extension at the joints, particularly the fingers, elbows, and knees. A predisposition to infections of the respiratory tract is a noteworthy feature.

The mode of genetic inheritance is a matter of controversy, and some pedigrees indicate that a single, recessive, autosomal gene is responsible, whereas others implicate a gene which is a sexlinked recessive. Helmholz and Harrington (1931), Halperin and Curtis (1942), and Jackson (1951) support the former, whereas Wolff (1942), Njå (1945-46), and Millman and Whittick (1952) adhere to the latter view. $\mathrm{Njå}$, indeed, equates the presence of clear corneae with sex-linked inheritance, and this paper-describes a British family in which the findings lend support to Njå's equation.

\section{Method of Investigation}

Two living cases, the second of which was discovered when working through the pedigree of the first, were examined by the author, and all the family histories were obtained personally and in conjunction with a social worker. A great deal of time was spent on the latter aspect of the investigation, and family witnesses were cross-checked after the completion of a questionnaire carefully designed to eliminate leading questions. Family albums and photographs were inspected and, where permission was obtained, copies made. Throughout, one was impressed by the intelligence of the relatives and in no witness was this considered to fall below average.

The diagnosis in three cases rests on a clinical examination, in four on a combination of photographic and lay descriptive evidence, in one on both medical and lay description, and in the remaining four on lay description alone.

\section{Case Reports}

Case 1.-This boy (Fig. 2, IV, 12, and Fig. 1), with whom the investigation began, is a typical gargoyle, aged $9 \frac{1}{2}$ years. Pregnancy and labour were normal. Teething began at 6 months, walking at $1 \frac{1}{2}$ years, and speech at $1 \frac{1}{4}$ years. The cranial circumference is increased and measures $22 \frac{1}{2}$ inches, the sagittal is $15 \frac{1}{2}$ inches and the lateral (earto-ear) 13 inches. The scalp hair is thick and coarse. The teeth are large and widely spaced. 


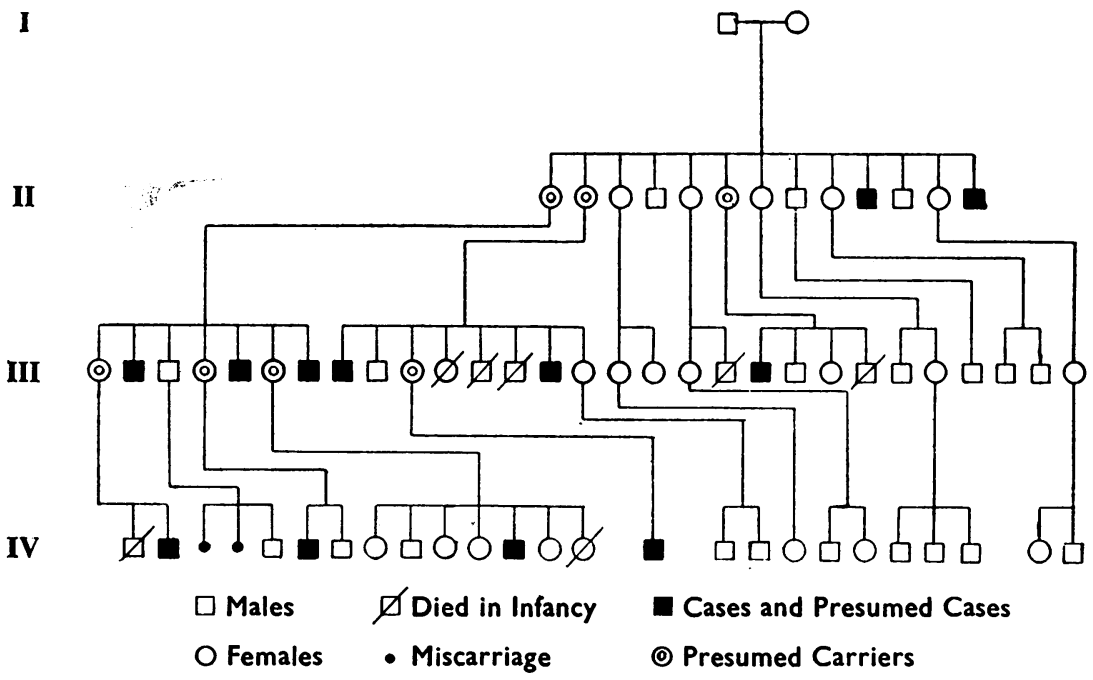

Fig. 2.-Pedigree of the affected family.

was made at 1 year. The cranial circumference is increased at 22 inches, the sagittal is 14 inches, and the lateral 13 inches. There are temporal bulges and the scalp hair is coarse. The teeth are very carious, the tongue enlarged and fissured, the lips thick, and the mouth a little open. The mandible and supraorbital ridges are prominent, the latter bearing bushy hair. The eyes are blue, the lashes long, and there is hypertelorism. The corneae are clear. The ears are low placed with large lobes, the nose squat, and the bridge depressed. The circumference of the chest at the nipple is 27 inches and the abdomen only 26

The mandible and the supra-orbital ridges are prominent, the latter bearing bushy hair. The infra-orbital areas are puffy and the cornea clear. The ear lobes are large and the nose broad with a somewhat depressed bridge. The neck is short and the shoulders hunched. At the level of the nipple the circumference of the chest is 28 inches, and at the umbilicus the protuberant abdomen measures $32 \frac{1}{2}$ inches. One scapula is considerably higher than its fellow, the liver is much enlarged, the spleen palpable, and the lower costal margin flared. The upper linib measures $14 \frac{1}{2}$ inches from the acromion to the radial styloid, and the lower 24 inches from the anterior superior iliac spine to the internal malleolus. The height is only 45 inches and the weight 78 pounds. The gait is waddling with a rigid, flat back, genu valgum, pes planus, and small patellae which are difficult to palpate. The genitals are poorly developed. The fingers, elbows, and knees are flexed, and extension in these joints is severely limited. The heart sounds are normal but the chest is very bronchitic and the child wheezes on moderate exertion. The skin is normal. His bodily development is rotund and, relatively, pyknic.

The boy is an imbecile and he would not cooperate in testing, and destroyed the test material. He is incontinent of urine and his habits are deteriorating.

Radiographs show an enlarged skull with an enlarged, deep, firmly lined sella turcica. The left coronal suture is a little open. The radii are somewhat deformed, the vertebrae ovoid with the first and second lumbar bodies basally hooked. The ribs are broadened in their anterior aspects.

Case 2.-This child (Fig. 2, IV, 15), aged $8 \frac{1}{4}$ years, is also a gargoyle, although his bodily configuration differs considerably from that of his half-cousin, Case 1. Pregnancy and labour were normal. Teething began at 4 months but decay was an early feature. He began to walk at 1 year 2 months and the first attempt at speech inches at the umbilicus. The liver is enlarged four fingerbreadths, but the spleen is not palpable. The upper limb measures 15 inches and the lower 264 inches. His height is 49 inches and weight 72 pounds. The gait is stiff but not waddling, and there is slight dorsolumbar kyphosis together with genu valgum and infantile genitalia. The hands are broad with incurved fifth fingers, slightly cyanotic nail beds, and clubbed thumb nails. The fingers are flexed and the movement of the joints of both upper and lower limbs is restricted. The heart and lungs are normal but he is " losing power in his legs ", is very apprehensive, and has many periods of diurnal whining and crying as though he were suffering abdominal colic. During these phases he seeks comfort from his mother. The skin is normal. His bodily development is angular and, relatively, asthenic.

$\mathrm{He}$ is imbecile and his habits are becoming faulty. He could not cooperate in mental testing.

Case 3.-This is the first gargoyle (Fig. 2, II, 10) appearing in the pedigree and, according to his mother who died recently aged 90 years, he was the first case in the line of descent within her memory.

He died in a mental hospital aged 6 or 7 years. The records show that he was generally underdeveloped, with brown eyes and no abnormality in the corneae. He had a florid complexion, peg-like teeth, a tongue which tended to protrude, and a large umbilical hernia. He was unable to stand unsupported, made inarticulate noises, could do nothing for himself, and was faulty in his habits. He had no thumbs, except for a small, wart-like representation on the left hand. His weight was $39 \frac{1}{2}$ pounds and his stature small. Two sisters, aged 18 and 13 years respectively at the time of his death, describe him as having a " large, flat-looking face and a large stomach". Their additional information corresponds with the medical description. No abnormality was noted in the skin. 
His mental grade is given as idiot and the cause of death as pneumonia.

Case 4.-This child (Fig. 2, II, 13) died at the age of 7 years and was described by his sister, aged 20 years at the time of his death, as being "the same as his brother (Case 3) and his grand-nephew (Case 2)". A photograph hung in the home for many years and the sister was, therefore, very sure of the likeness. He had a large, flat face, large head, clear corneae, a prominent abdomen with a hernia, could not walk unsupported, and had difficulty with his joints. His skin was normal.

His mental grade was imbecile. The cause of death is not known.

Case 5.-This boy (Fig. 2, III, 2) died aged 7 years and was described by his mother as being "like his brothers" (Cases 6 and 7). He had a large head, flat face and squat nose, clear corneae, stiff joints with flexed fingers, and a large abdomen, but no rupture. His skin was normal.

His mental grade was imbecile and the cause of death pneumonia.

Case 6.-This boy (Fig. 2, III, 5), who died at 11 years of age in a mental hospital, was also described by his mother as being like his brothers (Cases 5 and 7). In addition to the information given under Case 5 he had a large rupture from birth. He was markedly short of breath, so that he did not go out much. The corneae were clear. Thyroid treatment did not produce any improvement in his condition. His skin was normal.

His mental grade was imbecile and the cause of death unknown.

Case 7.-This boy (Fig. 2, III, 7 and Fig. 3) died at 12 years of age and was described by his mother as having a large, round head with coarse hair, flat nose, low-

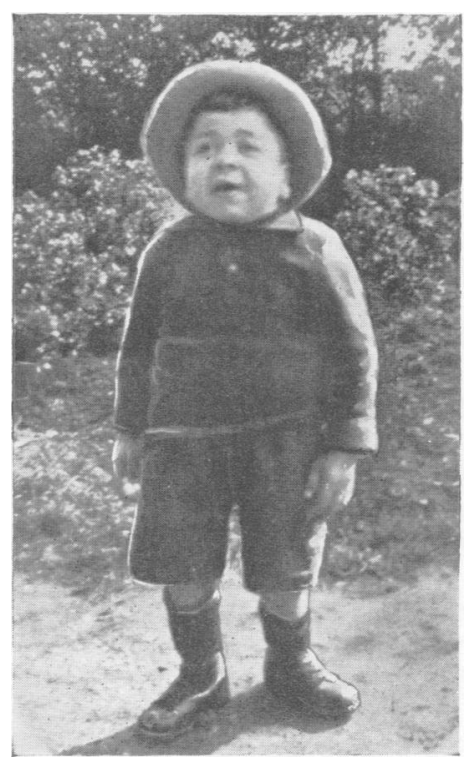

FIG. 3 placed ears, short neck, hunched shoulders, knock knees, and stiff shoulder, elbow, and knee joints. He was small and he was late in walking and talking. Extensive thyroid treatment did not produce any improvement. $\mathrm{He}$ had a large abdomen but no rupture. His eyes were " beautiful" and his corneae clear. The skin showed no abnormality, and he was rotund in build.

His mental grade was imbecile and the cause of death not known.
A photograph shows him to have been a gargoyle.

Case 8.-This child (Fig. 2, III, 8) died at the age of $5 \frac{1}{2}$ years in a, then, public assistance institution. Two aunts described him as being " the same as the others". His mother stated that he had a large head, prominent eyebrows, coarse hair, squat nose, normal-sized tongue and that he was capable of saying a word or two and of running about. He had a marked "stoop across his back" and had difficulty in moving his fingers and elbows. His corneae were clear. He had a large abdomen but no rupture, and his skin was normal.

His mental grade was imbecile and he died during a fit.

A photograph taken at the age of 4 years was inspected and the diagnosis confirmed.

Case 9.-This boy (Fig. 2, III, 14), when he died aged 5 years 8 months, could just walk by helping himself along the wall. His mother says that he was very small, had a large head, early dental decay, could not speak and that his abdomen was protuberant with a fair-sized umbilical hernia. The tongue was not noticeably enlarged, his corneae were clear, and his eyelashes "long and beautiful ". He had difficulty in straightening his arms and fingers. When shown a photograph of his cousin (Case 7), the mother said, " he's just like my son ". His skin was normal. His mental grade was imbecile. The cause of death is not known.

Case 10.-This child (Fig. 2, III, 20), who died at the age of 10 years, was described by his mother. Pregnancy was normal but labour was difficult and instrumental and he was born "with the cord around his neck". No abnormality was noted until he was 8 months old when his parents saw that his head was rather large and his general development slow. He did not walk until 2 years of age and only learned to say a few words during his lifetime. He had a large, globular head, with coarse hair and well marked eyebrows. There was infra-orbital puffiness and hypertelorism, but the corneae were clear. His ears were low placed, his nose squat and flat bridged, but his tongue was normal. The right shoulder was much higher than the left and both were hunched. His arms and fingers were stiff and he could not raise his hands above his head. The fingers were semiflexed. He always had difficulty in lifting his legs and, towards the end of his life, could not walk properly. His abdomen was protuberant but there was no hernia. Thyroid treatment produced no improvement. His configuration was rotund and his skin normal.

His mental grade was imbecile, his habits were unclean, he never gained bladder control, and he was destructive to property. The cause of death was recorded as cerebral haemorrhage.

A photograph, reproduction of which was refused, shows him to have been a gargoyle.

Case 11.-This boy (Fig. 2, IV, 2 and Fig. 4) died on his birthday at the age of 14 years. His mother's health during pregnancy was good, the birth full term and labour both natural and rapid. No abnormality was noticed during the early weeks, but he did not teeth until he was 


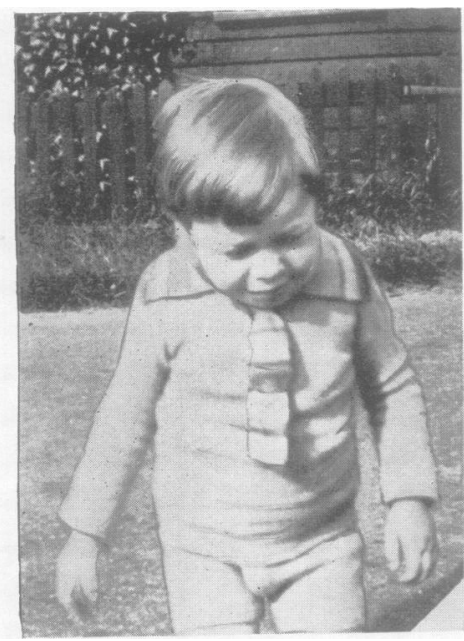

FIG. 4 nearly 2 years of age, nor walk until 3 years old. Speech was confined to a few simple words. He was described by his mother as having a largish head, with thick hair and bushy eyebrows. His nose was flat in appearance and his tongue rather large. He was subject to colds and bronchitis and was easily exhausted on walking. His corneae were clear.

His neck was short, his shoulders hunched, his elbows flexed and his fingers markedly so. He had difficulty in abducting his arms and in extending his elbows and fingers. Genu valgum was present, he stood badly, and could not fully extend his knees. Thyroid treatment over a period of years produced no improvement. His configuration was, relatively, asthenic, and his skin normal.

His mental grade was imbecile and his habits faulty. The cause of death was pneumonia.

A photograph shows him to have been a gargoyle.

Case 12.-This boy (Fig. 2, IV, 6) died at the age of 9 years. Pregnancy, term, and labour were normal, and no defect was evident at birth. The onset of teething, walking, and talking were within normal limits, but bladder and bowel control were very late. His mother described him as having a large, round head, with coarse hair, bushy eyebrows, flat nose, and protruding lips. His tongue was large and his corneae clear, but his neck was short and his shoulders hunched. His elbows and fingers were partially flexed. He had difficulty in moving his fingers, and his legs appeared stiff with a clumsy gait. The abdomen was not noticeably enlarged.

Hospital records show that at the age of 7 years 4 months his height was 43 inches and his weight 53 pounds. There was an apical systolic murmur and he was bronchitic, suffering much dyspnoea. His teeth were poor and his speech defective. Administration of thyroid from an early age produced no improvement. No abnormality was noted in his skin.

His mental grade was imbecile and the cause of death pneumonia.

He was diagnosed a gargoyle by a neurological consultant. His younger, and only, brother, born after a difficult labour, won a scholarship to a grammar school.

\section{Discussion}

Examination of the pedigree (Fig. 2) shows that males are exclusively affected, in the ratio to normal brothers, of approximately one half, and that the parents are, in each case, normal. Maternal uncles are affected in a total of 10 cases and maternal grand-uncles in four cases. Cousin relationships exist in six and four cases respectively in two generations. These findings indicate that the mode of transmission in this family is through a sex-linked, recessive gene.

There are no first cousin relationships in any of the parents and more remote connexions are denied, although it is difficult to be sure of the accuracy of the latter information. It would seem reasonable to suggest, however, that the condition originated as a mutation in the first female (Fig. 2, I, 2).

Certain easily recognized clinical manifestations occur in the pedigree, among which may be mentioned the variation in bodily type, the clear corneae, the consistently low-grade defectiveness, and the absence of skin lesions. The combination of clear corneae and normal skin is of interest when one remembers that the corneal epithelium and the epidermis each develop from primitive ectoderm.

As the literature on gargoylism extends it is becoming clearer that the syndrome, at one time considered as rather a composite entity, is more accurately described as an assemblage of additive signs. Jervis (1950) indicates that one or more of the outstanding peculiarities may be absent and Jackson (1951) doubts whether the name is a good one, especially where the face is not affected. Although formes frustes undoubtedly occur, the description in the majority of cases is so apt that it seems inadvisable to rename the syndrome, at least until the exact nature of the tissue deposit is elucidated. Lindsay, Reilly, Gotham, and Skahen (1948) consider this to be a combination of glycogen and protein which is laid down in both an extra- and intra-cellular manner. Should this substance, indeed, prove to be non-lipoid in structure it would appear that gargoylism can no longer be pathologically classified with the lipoidoses of Gaucher, Niemann-Pick, Schüller-Christian, or Tay-Sach.

From the clinical standpoint it seems appropriate that the term " gargoyloid" be reserved for deviants from the main syndrome, and a diagnostic scale of any agreed degree of accuracy, based on a factorial analysis, set up. This would be comparable to what Penrose (1949) has suggested for mongo!ism. Cases 1 and 2 in the present series are contrasting physical types in so far as body outline is concerned, as were Cases 7 and 11. Such a diagnostic scale would not, of course, preclude the inclusion of gargoylism within the framework of the chondroosseous dystrophies as a whole if, and when, a common genetic origin is revealed. 
In diagnosis it is certain that Helmholz and Harrington (1931) erred in placing so much emphasis on the presence of cloudy infiltration of the corneae. On the other hand more research is required before one can assume with $\mathrm{Nja}(1945-46)$ that sex-linked inheritance is always accompanied by clear corneae, although Millman and Whittick's (1952) cases and the author's series are substantially indicative of this possibility.

All the cases in the present family are, and were, mental defectives and this is in accord with most of the literature on the subject. Jackson (1951), Gilliland (1952), and Straus, Merliss, and Reiser (1947), however, describe cases with normal, or near normal, intelligence. It is reasonable to assume that the degree of intellectual impairment is dependent upon the amount of infiltration of the cerebral tissues. Consequently, where feasible, an assessment of intelligence by standardized methods should always be carried out, as it would be of interest to correlate the impairment, as registered by mental age, with the degree and location of extra-cerebral pathology. In so doing the possibility of an independent amentia, due to other causes, would necessarily have to be borne in mind. This point may have been overlooked by Ashby, Stewart, and Watkin (1937) when these authors dissociated neuronic histochemical changes and intellectual retardation on the evidence obtained from the findings in one of their cases.

The average age at death in the present series is 8.7 years, and it would be valuable, with safeguards, to be able to compare the equivalent average morbidity in a group with higher intelligence.

\section{Summary}

A British family containing gargoyles in three generations, all of whom exhibited clear corneae, low-grade defectiveness, and normal skin, and in whom two main types of body structure could be detected, is described. The pedigree demonstrates the presence of a sex-linked, recessive gene.

The institution of a diagnostic scale, and the necessity for assessment of mental age in cooperative individuals, is commented upon.

I am grateful to Professor E. W. Anderson for advice and criticism in the production of this paper, to Miss Mansell of the Public Health Department, Essex County Council, for her invaluable assistance with the social studies, and to all the relatives, without whose patient cooperation progress would not have been possible.

\section{REFERENCES}

Ashby, W. R., Stewart, R. M., and Watkin, J. H. (1937). Brain, 60, 149.

Ellis, R. W. B., Sheldon, W., and Capon, N. B. (1936). Quart. J. med., 29, (n.s.5), 119.

Gilliland, I. C. (1952). Proc. roy. Soc. Med., 45, 594.

Halperin, S. L., and Curtis, G. M. (1942). Amer. J. ment. Defic., 46, 298.

Helmholz, H. F., and Harrington, E. R. (1931). Amer. J. Dis. Child., 41, 793 . Hunter, C. (1917). Proc. roy. Soc. Med., 10, (Sect. Study Dis. Child.),

Hurler, G. (1919). Z. Kinderheilk, 24, 220.

Jackson, W. P. U. (1951). Arch. Dis. Childh., 26, 549.

Jervis, G. A. (1950). Arch. Neurol. Psychiat. Chicago, 63, 681.

Lindsay, S., Reilly, W. A., Gotham, T. J., and Skahen, R. (1948).

Amer. J. Dis. Child., 76, 239.
Millman, C. G., and Whittick, J. W. (1952). Journal of Neurology, Neurosurgery and Psychiatry, 15, 253.

Njå, A. (1945-46). Acta paediat., Uppsala, 33, 267.

Penrose, L. S. (1949). The Biology of Mental Defect. Sidgwick and Jackson, London.

Straus, R., Merliss, R., and Reiser, R. (1947). Amer. J. clin. Path., 17, 671 .

Wolff, D. (1942). Laryngoscope, St Louis, 52, 218. 